\title{
Problematic aspects and methods of developing leadership capabilities in young Chinese people
}

\author{
Maria Mizintseva \\ Department of Economics and Management \\ VINITI RAN \\ 20 Usievicha street, 125 315, Moscow \\ Russian Federation \\ Management Department, Economics Faculty, \\ Peoples' Friendship University of Russia (RUDN University) \\ 6 Miklukho-Maklaja Street, 125190, Moscow \\ Russian Federation \\ e-mail: mizintseva_mf@pfur.ru \\ Wenzhi Zhang \\ Management Department, Economics Faculty, \\ Peoples' Friendship University of Russia (RUDN University) \\ 6 Miklukho-Maklaja Street, 125190, Moscow \\ Russian Federation \\ e-mail: zhangwenzhi@mail.ru
}

\begin{abstract}
This paper investigates the problems of developing leadership capabilities in young Chinese people. It analyses youth as a socio-demographic category, characterizes the key specific features of the Chinese young generation including their typical parameters. The article also interprets the problems in the youth labor market, among which the author singles out the problems of high real unemployment rate, age discrimination and imbalances in the labor market, migration of young people to other countries, the phenomenon of nowhere working and nowhere learning young people, outflow of highly qualified young personnel abroad, etc. The author distinguishes the key areas and methods for developing the leadership qualities in Chinese young people, including the organization of centers for the young people retraining for sought-after specialties, within which it is possible to open leadership programs, to establish within the Ministry of Youth a separate department for youth development and adaptation to the national labor market, the creation of leadership camps, schools, etc. The author concludes that the development of leadership capability in the young Chinese has a positive influence on the modern-day labor market and the economy as a whole in the country provided that they take into account the national mentality and traditions.
\end{abstract}

\section{Introduction}

The historical, cultural, political and economic characteristics of China explain the specificity of youth as a socio-demographic category of the population, as well as the young professionals labor market. Thence, the Chinese model of the labor market does not look like any typical model (neither Japanese, nor Swedish, nor American). The Chinese model of the labor market is characterized by: strict control over labor relations and high social security of employees at state enterprises; a total absence of legal regulation and protection of private companies employees; abundant labor supply in the labor market in many parts of the country; age discrimination in the labor market; labor supply and demand imbalance; the difficulty in finding a job for talented and skilled youth, a sharp decline in wages, which led to an outflow of the best specialists, including young people abroad. This is the compelling reason for searching for new pathways and methods for improving labor market management mechanisms, among which we can distinguish the training of young Chinese, including in the field of self-employment, for which leadership qualities are absolutely necessary. And although modern Chinese young people are more flexible and self-confident compared to their parents, however, the traditional way of life and family pressure have a serious impact on the young Chinese, who in leadership qualities and skills are seriously inferior to those of the same age who live in the West. The above mentioned explains the relevance of the analysis of Chinese young generation as a socio-demographic category, the study of the main trends in the youth labor market in China, as well as the identification of the most important vectors for developing the leadership capacities of young Chinese people.

Classical scholars of leadership management in the global academic literature, undoubtedly, are the following: Stogftll (1974), Mann (1959), Likert (1967), Lewin (1939), and Bennis (1989). The problems of the 
labor market in China, including the youth labor market, were examined by Cheng (2002), Ji (2013), Zhaoxia (2017), Peng (2010), Leigh (2015). In addition, characteristic features of modern Chinese youth are considered in the works Tang (2015), Zhocao (2014), or Zhaoxia (2016). Nevertheless, we have to state that there is not enough research on the development of Chinese youth leadership qualities in the scientific literature, there are no methods for teaching young Chinese leadership skills and tapping leadership potential.

\section{Chinese youth as a prospective socio-demographic category}

In China, according to the Sixth National Population Census conducted by the government in 2010, the total population amounted to 1339.72 million people. (Communiqué of the sixth All-China Population Census, 2011) In 2015, according to UN reports, the population in the country was 1376.04 million people, and in 2016 - about 1380 million people. (Figure 1). (Portal Census Taker) The age structure at the beginning of 2016 in China was as follows: 242289325 people - under 15 years of age, 1013336394 people - from 15 to 65 and 121957437 people - over 65. (United Nations Statistics Division) One of the most serious problems in China today is the rapid aging of the population. So, according to the experts in the field of China population, approximately $13 \%$ of the population are people over 60, which corresponds to five working citizens per pensioner. By 2020, it is expected that three people will have to work for one pensioner, and in the future the situation will worsen even more. (Sinospaces.ru) Today, China is already called the oldest country in the world, the country of retirees.

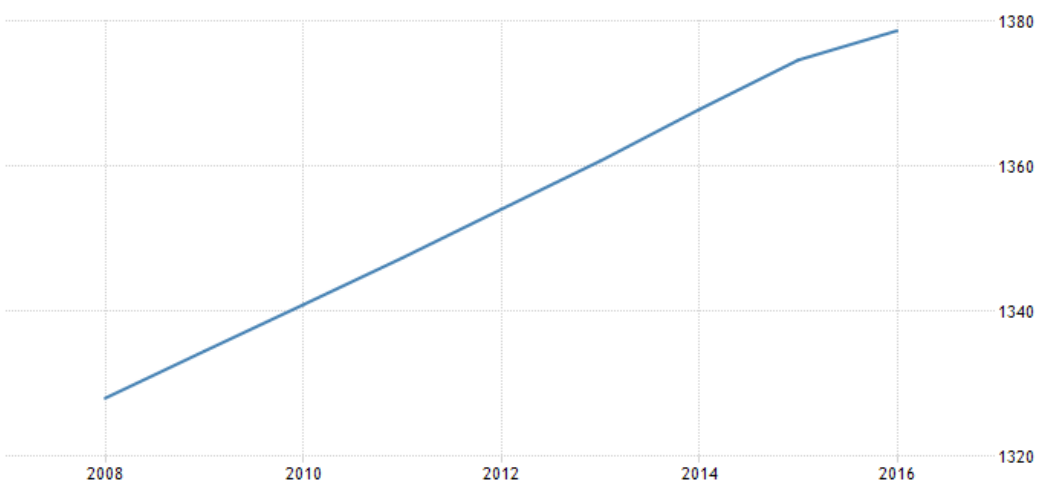

Fig. 1. Chine's population, thousand people

Source: Trading Economic (2018)

In China, since 2010, there have been slightly more than 370 million young people. They form the age group from 16 to 35 years of age. Most of them are children born in the 1980s and 1990s. First and foremost, it is necessary to emphasize once again that most Chinese families have one child, traditionally parents invested in the only child maximum material and spiritual efforts. As a result, today a great number of young people under 30 years of age and more live with their parents, and many of them still do not work anywhere. According to the media, young people dependent on their parents' money amount to almost a half of all young people in China, although the state statistics agencies do not confirm this figure.

Thus, China, as other countries of the world, witnesses the increase in the number of nowhere working and nowhere learning young people (the phenomenon of neet - not in employment, education or training) (Report by the Social Exclusion Unit 1999; Coppola et al. 2015). This phenomenon provokes the rise in criminality, drug addiction and other socially negative trends and become a serious problem of the present and future society. Thus, the European Commission considers the main tasks of youth work as follows: minimizing the level of youth unemployment and reducing the number of neet-youth. (European Commission 2010) Moreover, a high percentage of nowhere learning and nowhere working young people is high in Latin America, Africa, European and relatively prosperous Asian countries (including China). For example, in Greece, Italy, and Spain the neetyouth rate is up to $22 \%$. (Varshavskaya 2015) In China, thisstatistics goes unreported, but a number of Chinese specialists engaged in youth employment are increasingly speaking about this phenomenon, which has been and will continue to be a serious problem for current and future generations of young people in all countries, including China.

Today, the modern generation of China is very different from the generation of their parents. Many young people believe that there should be more than one child in the family, that women have the full right to work on an equal footing with men, to share equally family obligations and even have a serious job position. Modern Chinese youth, as a rule, is distinguished by a higher self-esteem, a desire for self-realization, an orientation towards high mobility. They are more flexible, open, individualistic than their parents. Young people in China are more concerned with the issues of personal development (76\%), national evolution (19\%), common 
humanity (16\%), (Trotsuk and Skrynnikova 2014) which is evidenced by the fact that the current younger generation of China is more targeted, first of all, at themselves and at their own self-realization.

Thus, the development of leadership qualities and skills for Chinese youth today is not only timely, but also an urgent task due to the fact that the development of leadership potential contributes to the better young people' activities in the labor market (opening their own business, obtaining employment in remote forms or higher positions (for example, middle managers). However, it is not enough to establish the system for leadership skills development (there are virtually no programs on leadership at the country's universities, as well the leadership schools are not popular, etc.)

\section{Problems and trends in the youth labor market of China}

In addition to the serious neet problem, mentioned above, China today witnesses a migration of young people to other countries of the region, as well as to other countries in the world. There is a large migration flow to the USA $(52 \%)$ and Canada - 21\% (Figure 2). (www.chinafile.com)

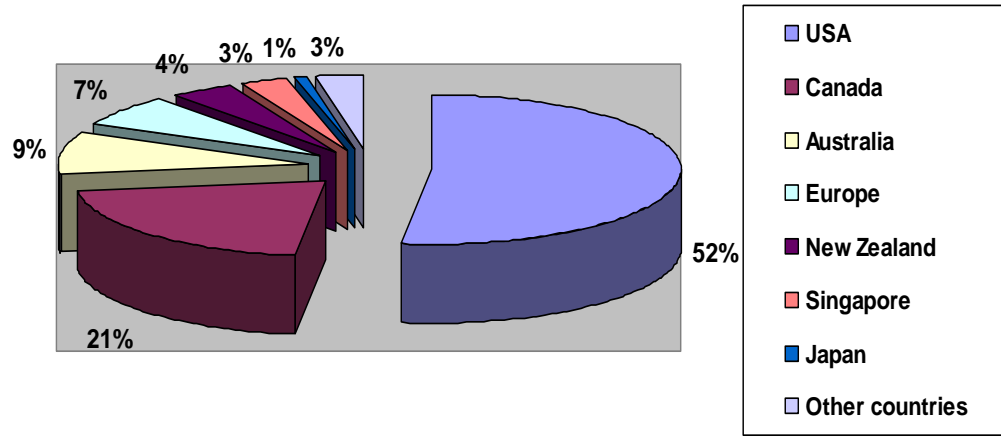

Fig. 2. Structure of migration flows from China to other countries, 2016. Source: Own results

According to various estimates, the number of "new" migrants leaving China is estimated at several hundred thousand to 1.5 million people per year. According to the calculations made by American professor J. Goldstone, in the 1980s and early 1990s every year 180 thousand migrants left the country (Smith 1997). Chinese professor Zhuang Gotu gives similar assessments, he points to 1.425 million people who left for developed countries and 100-200 thousand people for developing countries (Thailand, Philippines, Indonesia and Malaysia) during the period. (Research on the Chinese going abroad 1997) Other experts assess the number of migrants who left China at the same time, at 270 thousand people per year. (www.iussp.org) Now the Chinese work in 180 countries. The biggest part of them work in Asian countries.

The structure of international labor migration in the world tends to rejuvenate. Thus, according to the United Nations (2015) Population Fund, young people between 15 and 25 years of age currently make up about $30 \%$ of labor migrants around the world. The lack of decent employment opportunities in developing countries has led to a significant increase in the emigration of many young workers, both low- and highly-skilled ones. Young migrants were particularly affected by the global crisis of 2008. (International migration in a globalizing world 2011) In China, the rejuvenation of migration flows is also significant.

This is due, not least, to the fact that in China there are practically no programs to support young university graduates, including talented young professionals. On the contrary, young people who have received a good education (including at well-known foreign universities) are forced to agree to smaller salaries, as well as to a longer career pathway. In addition, China today experiences a high rate of real youth unemployment (according to some sources, up to $30 \%$ ). This contributes to the formation of a separate group of Chinese young people, who prefer to leave for other countries, including neighboring ones. Many of the young professionals change their field of activity or search for jobs in other countries of the world, mostly in South-East Asia, located in the neighborhood of the PRC (Singapore, Malaysia) or abroad (Australia, Canada, USA). Thus, in China, the problem of "brain drain", the outflow of qualified, well-educated young people, is becoming more and more intense. For example, the People's Daily, stated that China has ranked first in the world in terms of "brain drain" - $87 \%$ of talented Chinese specialists do not return home after studying or working abroad.

\section{Methods of developing young Chinese people leadership capabilities}

As a rule, experts and researchers in this field consider the following qualities as the essential features of leadership: riskiness, energy, ambition, public-speaking abilities, ability to communicate with people, the ability 
to lead people and encourage them with ideas, high professionalism, sense of humor, flexibility, etc. In China, where traditionally young generations learned the values of patience, balance, collectivism, while individualism and ambition were considered undesirable, leadership has not been encouraged for a long time. However, it should be noted that with the arrival of Western companies with their specific values, culture and behavioral norms, the situation in China began to change. Western values and culture in recent decades have seriously affected young Chinese, but in terms of leadership qualities, Chinese youth are still lagging behind Western peers (Table 1.).

Table 1. The key characteristics of an individual in western and oriental cultures

\begin{tabular}{|c|c|}
\hline Characteristic qualities of the Western & Characteristic qualities of the oriental \\
individual & individual \\
\hline Individualism & Collectivism \\
Willingness to risk & Prudence \\
Self-righteousness & Tactfulness \\
Openness & Closeness \\
Ambitions & Modesty \\
\hline
\end{tabular}

Source: Own results

Given the high rate of young people migration from the country, the need to adapt to other cultural environment and to keep up with the times, there is a necessity to pay increasing attention to the development of leadership qualities in Chinese youth. Among the main measures used to develop leadership qualities in Chinese youth, first of all, we can name the professional guidance - the activity of specialized bodies to familiarize young people with the peculiarities of specialties, their economic and social significance and the requirements they impose on the employee, with the purpose of helping people in choosing the type of work, specialty and profession. This activity must be conducted at secondary schools. It should involve both teachers and representatives of state bodies, specialists of agencies in the labor market, as well they can attract business representatives and talented young people who made progress, seemingly, in the low-status areas of the economy. The most important activity in professional guidance is fostering the foundations of leadership behavior in the young Chinese, as well as the basic skills of self-motivation, self-training and self-development.

It seems advisable to establish specialized centers for vocational training and retraining of young personnel in the country. In addition to the courses and trainings of these centers it is useful to introduce programs for training leadership qualities and skills. Such centers can be an active participant in the labor market, acting as an intermediary between unemployed people with high qualifications and companies. Universities, research centers, private training companies, relevant agencies and departments in ministries, etc. can become participants in the retraining process. So, among the basic functions, along with the function of further young people employment, such centers can carry out social (preferences, benefits), psychological (psychological counseling) and professional support (vocational guidance, professional retraining, professional counseling, leadership development and training).

The "Law on the Youth of China", which was adopted in 1997, declared as the main principle the full and comprehensive involvement of young people in economic and labor activities. However, this task has not been fully implemented. So, until now there is no full distribution of graduates of higher educational institutions to jobs in accordance with the qualifications received by graduates; work with young people is not enough organized, including work placement at the regions of their residence; youth public organizations are not sufficiently funded, etc. Thus, the author considers it important to strengthen work with young people, including the development of their leadership skills, after obtaining which young Chinese could not only become competitive in the country's labor market, but also be able to set their own business, work remotely, be more active and self-confident.

Traditionally self-employment is popular in China and realized in the form of small enterprises. For China, self-employment is an effective tool. In order to reduce unemployment rate, the government can maintain this practice. It seems advisable here to include in the process of self-employment specialized companies (as well as labor exchanges) that would provide some assistance in establishing and organizing private businesses (for example, training those wishing to become a small entrepreneur or consulting on legal, economic and organizational matters).

It is necessary to introduce in the curricula of national universities training courses on leadership, organize master classes and trainings carried out by leading managers of the country and well-known foreign companies, reveal the leadership potential of young people through activating extracurricular activities, etc. (Fig.3). 


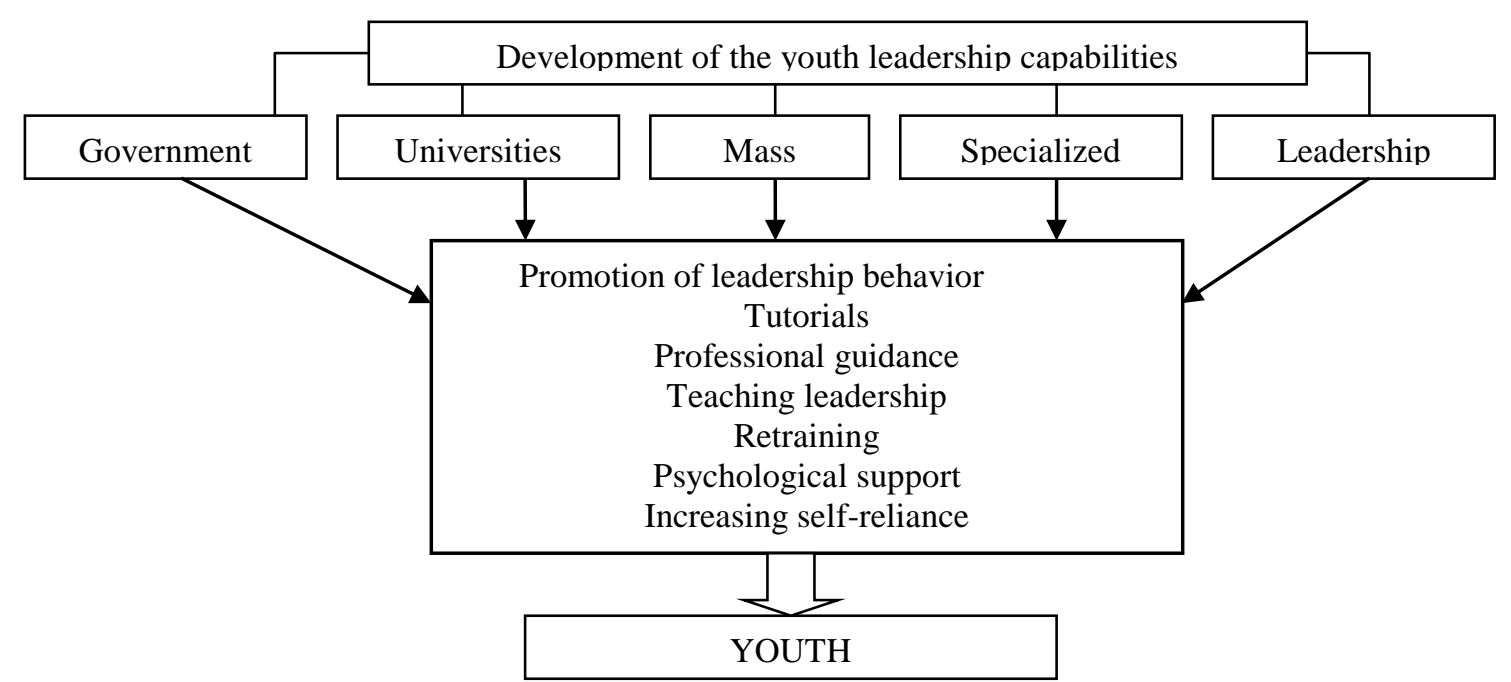

Fig. 3. Key methods for developing young Chinese leadership Source: Own results

In general, it is important to emphasize that, in the context of rapid social and economic transformation and the strengthening of globalization processes, the development of leadership skills and potential of Chinese youth can have a positive impact on the development of the modern labor market in the country and the economy as a whole. Nevertheless, the preservation of national specific features also remains important, therefore, all Western programs and leadership tools should be adapted to the national mentality and traditions of Chinese society.

\section{Conclusions}

The aim set in the paper was to identify the problematic aspects and methods for developing leadership qualities in Chinese youth. We can conclude that the characteristic features of the China's youth have been studied, key problems that hamper the development of the leadership potential of the younger generation of the country have been identified, a brief analysis of the labor market for young people in China has been conducted, and important methods for developing leadership capabilities and skills have been proposed for young Chinese people, taking into account traditional features and national mentality.

The materials, findings, provisions and conclusions of this article can help further study this issue in scientific community, as well as assist the development of the modern Chinese youth market. The research is conducted at the Management Department, Economics Faculty, RUDN University, which has a long history and experience with similar studies. Thence, the implementation of this research might be useful and important for various stakeholders and politicians.

\section{References}

Bennis W, On Becoming a Leader, $1^{\text {st }}$ edn. (Addison Wesley: New York, 1989), 202 p.

Bridging the gap (1999) New opportunities for 16-18 year olds not in education, employment or training. Report by the Social Exclusion Unit. http://dera.ioe.ac.uk/15119/2/bridging-the-gap.pdf Accessed 05 Sep 2018

Cheng Ch, The formation of the China's labor market. The dissertation for a Candidate Degree in Sociological Sciences (Moscow, 2004)

Chinese youth (2011) https://rus.azattyq.org/a/china_youth_parents_marriage/24347156.html Accessed 5 Sep 2018

Communique of the sixth All-China Population Census (2010) Population Division of the Department of Economic and Social Affairs of the United Nations Secretariat, World Population Prospects: The 2010 Revision. http://www.un.org/en/development/desa/population/publications/trends/populationprospects 2010_revision.shtml Accessed 28 Aug 2018

Coppola G, O'Higgins N, Youth and the Crisis: Unemployment, Education and Health in Europe, $1^{\text {st }}$ edn. (Routledge: New York, 2015), 294 p. 
European Commission (2010) Europe 2020: A strategy for smart, sustainable and inclusive growth. Brussels. https://www.eea.europa.eu/policy-documents/com-2010-2020-europe-2020. Accessed 27 Aug 2018

Illegal migrants from China/ Huang Runlong (2001) XXIV IUSSP general Population Conference, Salvador, Brazil 18- 24 August 2001. http://www.iussp.org/Brazil2001/s20/S27_P03_Huang.pdf. Accessed 5 Sep 2018

Ji T (2013) Labor market state regulation in of Russia and China for youth employment and the trend of their employment. Humanitarian, socio-economic and social sciences. 5: 108-114.

Leigh A, Human resources development, $1^{\text {st }}$ edn. (Publishing house of the machine-building industry: Beijing, 2015), $220 \mathrm{p}$.

Lewin K, Lippitt R, White R (1939) Patterns of Aggressive Behavior in Experimentally - Created Social Climates. Journal of Social Psychology. 10 (2): 271-301. doi:10.1080/00224545.1939.9713366

Likert R, The Human Organization, $1^{\text {st }}$ edn. (McGraw - Hill, 1967), 258 p.

Mann R (1959) A review of the Relationships between Personality and Performance in Small Groups. Psychologocal Bulletin 56(4):241-270. doi: 10.1037/h0044587

Peng U.D (2010) Labor migration from the People's Republic of China under the conditions of increasing openness of the economy. Bulletin of the Polotsk State University. Series: Economy and Law.10: 52-61.

Portal “Census Taker”. http://countrymeters.info/ru/China Accessed 23 Jul 2018

Pro utechku Mozgov iz Kitaya (2014) http://www.daokedao.ru/2014/08/07/pro-utechku-mozgov-iz-kitaya/ Accessed 8 Aug 2018

Site "Chinese spaces".http://sinospaces.ru Accessed 5 Aug 2018

Site of Trading Economics. http://ru.tradingeconomics.com/china/population Accessed 23 Aug 2018

Smith P, Paul J, Human smuggling: Chinese migrant trafficking and the challenge to America's immigration tradition $1^{\text {st }}$ edn. (Center for strategic and international studies:Washington, 1997), $63 \mathrm{p}$.

Stogftll R, Handbook of Leadership, $1^{\text {st }}$ edn. (The Free Press: New York, 1974), 576 p.

Tang F (2015) Psychological features of interaction between generations in China exemplified by family relations. The world of science, culture and education 5(54):249-251.

Trotsuk I.V., Skrynnikova M.P., Ji Jinfeng (2014) Priorities of Chinese youth in the professional sphere and the status of young professionals in the labor market of the PRC. Theory and practice of social development.12:4145.

United Nations (2015) Statistics Division. http://unstats.un.org/unsd/default.htm Accessed 12 Sep 2018

Varshavskaya E.Ya (2015) Young people excluded from employment and education in the EU and Russia. Statistical issues. 4:40-47.

Wealthy Chinese Are Fleeing the Country Like Mad (2015) A China File Infographic Translation. http://www.chinafile.com/multimedia/infographics/wealthy-chinese-are-fleeing-country-mad Accessed 3 Sep 2018

Zhaoxia E (2016) Chinese youth attitude towards marriage. Economics, Sociology and Law 12:90-92.

Zhaoxia E (2017) Problems of the labor market in China. Advances in modern science 8(4): 118-121.

Zhocao Yu (2014) Demographic factors of China's socio-economic development. Economic theory 11(1): 85-91.

Zhuang Guotu (1997) 对襟 20 年华人国际移民活动的继继 (Reflections on several features of Chinese migration in the last 20 years). Research on the Chinese going abroad 2:3.

中国公民境外就业发展展露研究 (2011) Study of the strategy for employment developing for Chinese citizens abroad. International migration in a globalizing world: The role of youth, Technical Paper. http://www.isis.net.cn/nl196/nl316/n2027/1200621.html Accessed 01 Jul 2018 